\title{
Level of Campylobacter jejuni from naturally contaminated chicken liver and chicken legs in various task: a cross contamination study
}

\author{
${ }^{1 *}$ New, C.Y., ${ }^{1}$ Wong, C.Y., ${ }^{1}$ Usha, M., ${ }^{1}$ Ubong, A., ${ }^{3}$ Nakaguchi, Y., ${ }^{4}$ Nishibuchi, M. \\ and ${ }^{1,2}$ Son, $\mathrm{R}$. \\ ${ }^{1}$ Department of Food Science, Faculty of Food Science and Technology, \\ Universiti Putra Malaysia, 43400 UPM Serdang, Selangor Darul Ehsan, Malaysia \\ ${ }^{2}$ Food Safety and Food Integrity, Institute of Tropical Agriculture and Food Security, \\ Universiti Putra Malaysia 43400 UPM Serdang, Selangor, Malaysia \\ ${ }^{3}$ Faculty of Bioresources and Environmental Sciences, Ishikawa Prefectural University, \\ Nonoichi City, Ishikawa Prefecture, Japan \\ ${ }^{4}$ Centre for South Asia Studies, Kyoto University, 46 Shomoadachi-cho, Yoshida Sakyo-ku, \\ Kyoto 606-8510, Japan
}

\section{Article history: \\ Received: 20 February 2017 \\ Received in revised form: \\ 6 March 2017 \\ Accepted: 8 March 2017 \\ Available Online: \\ 10 March 2017}

\section{Keywords:}

Campylobacter jejuni

Chicken liver and leg

Cross contamination

DOI:

http://doi.org/10.26656/ fr.2017.2.010

\begin{abstract}
Cross contamination is one of the most important contributing factors in foodborne illness originating in household environments. The objective of this research was to determine the transfer between naturally contaminated chicken liver and leg to cutting board, hand glove, knife and cucumber, during slicing. The microorganism tested was Campylobacter jejuni and the results showed that the pathogen transferred to all utensils, at different transfer rate, despite the low level of the naturally contaminating pathogen. With unknown concentration bacteria in the naturally contaminated samples, a proportion of the utensils were still contaminated with $C$. jejuni and not surprisingly, when the sample were contaminated with higher concentrations of the pathogen, a higher proportion of the utensils had detectable C. jejuni cells present, though in many cases cross contamination seems to be a random event. Transfer of the naturally contaminating $C$. jejuni from the chicken liver and leg to the utensils were $<3.0$ to $9.2 \mathrm{MPN} / \mathrm{g}$ and $<3.0$ to $3.0 \mathrm{MPN} / \mathrm{g}$, respectively. The results of this study highlighted the potential for cross contamination of food borne pathogens in the kitchen environment.
\end{abstract}

\section{Introduction}

Occurrence of foodborne illness is a public and clinical health problem causing economic losses related to lower work productivity, hospitalization, and other health care expenses. Campylobacter species belong to the major group of foodborne pathogens which cause gastroenteritis (Wingstrand et al., 2006; Fischer et al., 2007) in humans in both developed and developing countries. The pathogen is commonly associated with livestock products along with other foodborne pathogens such as Salmonella, Escherichia coli O157:H7 and Yersinia in Malaysia (Government of Malaysia, 2004). Campylobacter spp. topped the charts as the top five pathogens contributing to domestically acquired foodborne illnesses, and resulting in hospitalization and in death (Centers for Disease Control and Prevention (CDC), 2016). The main causative agent of most human illness is caused by one species, called Campylobacter jejuni although there are other species that can caused human illness too. It is reported that $C$. jejuni is the second most common bacterial cause of diarrhea in the United States with most cases occur as isolated, sporadic events, not as part of recognized outbreaks (CDC, 2014).

Microbial cross contamination refers to the transfer, direct or indirect, of microorganisms (bacteria, virus, parasites, or fungi) from a contaminated item to a non-contaminated item. In foods, cross contamination of foodborne pathogens is a major concern as it increases the risk for humans to ingest contaminated food and become ill. Various researchers have reported that cross contamination and inadequate cooking are the most important factors that determine the food safety during meal preparation. The complexity of the food chain exacerbates the matter as cross contamination can occur in various ways.

At the consumer phase level, cross contamination usually occurs from the contaminated raw materials to kitchen materials to non-contaminated food products. Similarly, it could also occur through the transfer of pathogens to hands of the food handlers 
to non-contaminated food products. Unfortunately, many consumers are still unaware that domestic food contact surfaces and utensils are considered a contributing factor to transmission and the occurrence of sporadic foodborne disease (Bloomfield, 2003; Perez-Rodríguez et al., 2008). Hence, this study aimed to determine the $C$. jejuni cross contamination rate from naturally contaminated chicken liver and chicken leg to kitchen utensils and hands to mimic scenario of cross contamination at consumer phase level. The relative importance of the microbial safety to foodborne illness remains unclear to consumers which emphasized the need to conduct more studies to establish intervention measures for prevention and control of the major foodborne pathogens, especially the thermophilic Campylobacter spp. that represent a major source of human infections.

\section{Materials and methods}

\subsection{Sample collection}

Chicken liver and chicken legs were purchased from a local hypermarket in Serdang, Selangor and examined for the presence of $C$. jejuni. At the time of their use in experiments, all livestock products were deemed to be in a "fresh and naturally contaminated with pathogen" state.

\subsection{Kitchen utensil description and maintenance}

Stainless steel knife (blade size of $17 \mathrm{~cm}$ in length and $2 \mathrm{~cm}$ width at the base), sterile latex disposable latex gloves and cutting board (wooden type; $30 \mathrm{~cm} \mathrm{x}$ $22 \mathrm{~cm}$ ) were selected as commonly available kitchen utensils in the consumers' kitchen. The same knife and cutting board were used multiple times throughout the study. To sterilize the utensils between uses, knives and cutting board were autoclaved at $121^{\circ} \mathrm{C}$ for $15 \mathrm{~min}$ to ensure that residual pathogens that might have lodged in cracks or crevices on the items during a previous trial were inactivated. To remove rust spots that occurred on knives after autoclaving, knives were brushed with a scouring pad.

\subsection{Cross contamination study design}

Using a sterile hand glove, a liver or a chicken leg was placed on the cutting board and was sliced into small pieces using a sterile knife. Ten gram of the sample was placed in $1500 \mathrm{ml}$ Whirl-pak ${ }^{\circledR}$ bag containing $90 \mathrm{ml}$ of Bolton broth for pathogen analysis. A cucumber was placed at the exact location where the chicken liver or chicken leg was cut, and using the same knife the cucumber was cut into small slices. Likewise, ten grams of the sliced cucumber was weighed into $1500 \mathrm{ml}$ Whirl-pak ${ }^{\circledR}$ bag containing 90 $\mathrm{ml}$ of Bolton broth. Samples were then plunged using a stomached machine for 60 seconds. Swab samples from the cutting board, the knife and the latex gloves were taken and dipped into $9 \mathrm{ml}$ of Bolton Broth. The broth containing the swab samples were vortexed vigorously for 2-3 minutes and allowed to stand for 1 minute. 5 replicate observations were performed for the cross contamination study.

Most Probable Number (MPN) technique was employed to enumerate the bacterial concentration. One $\mathrm{ml}$ of each sample was added to $9 \mathrm{ml}$ of Bolton broth, and dilutions of $1: 100$ and 1:1000 were prepared from the stomached fluid in triplicate following three-tubes MPN format. All MPN tubes were incubated in anaerobic jar under microaerophilic conditions produced using Anerocult $\mathrm{C}$ system (Merck, Germany) at $37^{\circ} \mathrm{C}$ for 48 hours. Turbid tubes were recorded as positives and further subjected to PCR detection for $C$. jejuni.

\subsection{PCR detection of Campylobacter jejuni}

DNA was extracted using the boiled-cell method. Five hundred micro-litres of the broth from the turbid tubes were transferred into a clean $1.5 \mathrm{ml}$ microcentrifuge tubes and centrifuged at 12,000 rpm for $3 \mathrm{~min}$ in order to pellet the bacterial cells. The pellet was then re-suspended in $400 \mu \mathrm{l}$ of sterile distilled water, and boiled for $10 \mathrm{~min}$ followed by freezing at $-20^{\circ} \mathrm{C}$ for $10 \mathrm{~min}$. It was then centrifuged at $10,000 \mathrm{rpm}$ for $5 \mathrm{~min}$ and the supernatant was then kept at $-20^{\circ} \mathrm{C}$ for use in PCR.

DNA from boiled lysates was subjected to PCR detection for C. jejuni. All PCR was performed in $25 \mu \mathrm{l}$ of reaction mixture containing $1 \mathrm{X}$ PCR buffer, $0.2 \mathrm{mM}$ of dNTPs mix, $2.5 \mathrm{mM} \mathrm{MgCl} 2,0.25$ $\mathrm{U}$ Taq DNA polymerase, $0.4 \mu \mathrm{M}$ of each primer (HIP400F, 5'-GAA GAG GGT TTG GGT GGT-3' and HIP1134R, 5'-AGC TAG CTT CGC ATA ATA ACT TG-3') (Linton et al., 1997) and $2 \mu$ of DNA boiled-lysate. The entire PCR assay were subjected to the initial denaturing at $94^{\circ} \mathrm{C}$ for $2 \mathrm{~min} ; 27$ cycles of denaturation at $94^{\circ} \mathrm{C}$ for $1 \mathrm{~min}$, annealing at $58^{\circ} \mathrm{C}$ for 1 minute, extension at $72^{\circ} \mathrm{C}$ for 1 minute; and a final extension at $72^{\circ} \mathrm{C}$ for 10 minutes. $10 \mu \mathrm{l}$ of the amplification products were electrophoresed in 1.0\% agarose gel electrophoresis, producing a fragment of 735-bp of the hippuricase (hipO) gene specific for $C$. jejuni. 


\section{Results and discussion}

Campylobacter is a major bacterial cause of infectious diarrheal illness in many countries. Handling and consumption of animal products, in particular poultry, has been identified as important risk factors leading to major risk of human campylobacteriosis. To date, there are no published researched that quantifies the cross contamination rate from naturally contaminated livestock products to the cutting board, knife, latex gloves and other food products, particularly, in a scenario mimicking the home kitchen environment. Raw ingredients that are contaminated with foodborne pathogens are handled without proper food safety measures in common households. The outcome of this present study will provide a real picture to understand the underlying transmission risk factors in contributing to foodborne illness acquired domestically.

The concentration of $C$. jejuni present from the naturally contaminated chicken liver, and transferred to the cutting board, knife, cucumber and latex were tabulated in Table 1, while Table 2 represents the concentration of $C$. jejuni present from the naturally contaminated chicken leg, and transferred to the cutting board, knife, cucumber and latex gloves.

Overall, the chicken liver samples had higher density of $C$. jejuni compared to the chicken leg samples in this study with the concentration ranged from $<3.0-6.1 \mathrm{MPN} / \mathrm{g}$ and $<3.0 \mathrm{MPN} / \mathrm{g}$ respectively. Nur Ilida and Faridah (2012) reported that the prevalence of $C$. jejuni detected from fresh raw chicken were higher for chicken liver than chicken leg which showed similarity with our results. The result also showed the non-homogenous distribution of the pathogens in the naturally contaminated samples. $C$. jejuni were not detected in the representative samples of chicken liver and chicken leg. However, C. jejuni was detected randomly from the utensils used and from the cucumber slices. This reflects the true nature of the distribution of pathogens in raw foods and further explains why consumers purchasing the same batch of raw food may be exposed to different level of risk. The results of our study inferred that the cutting board and knife used had a larger surface area of contact with the naturally contaminated chicken liver and chicken leg which increases the contact and adherence of the $C$. jejuni from the naturally contaminated chicken liver and chicken leg to the cutting board and knife. The results also indicated that an obviously high transfer ratio of the naturally contaminating $C$. jejuni from cutting board was higher than from the knife. The surface characteristics of the cutting board (e.g., roughness, stomata, crevices, total surface, etc.) render them an ideal surface for bacterial adhesion and favour the existence of the bacteria on them.

Table 1. Concentration of $C$. jejuni transferred from chicken liver in various tasks of the cross contamination study.

\begin{tabular}{|c|c|c|c|c|}
\hline \multirow{2}{*}{$\begin{array}{c}\text { Sample/Transfer } \\
\text { description }\end{array}$} & \multirow{2}{*}{$\begin{array}{l}\text { Number of } \\
\text { Observations }\end{array}$} & \multicolumn{3}{|c|}{$\begin{array}{c}\text { Concentration of } C \text {. } \\
\text { jejuni }(\mathrm{MPN} / \mathrm{g})\end{array}$} \\
\hline & & Min & Med & Max \\
\hline Chicken Liver & 5 & $<3.0$ & 4.55 & 6.1 \\
\hline $\begin{array}{l}\text { Chicken Liver to } \\
\text { Cutting Board }\end{array}$ & 5 & $<3.0$ & 6.1 & 9.2 \\
\hline $\begin{array}{l}\text { Chicken Liver cut } \\
\text { with knife }\end{array}$ & 5 & $<3.0$ & 3 & 7.4 \\
\hline $\begin{array}{l}\text { Cucumber cut with } \\
\text { knife on cutting board }\end{array}$ & 5 & $<3.0$ & 3 & 3 \\
\hline Latex Gloves & 5 & $<3.0$ & 3 & 3 \\
\hline
\end{tabular}

Table 2. Concentration of $C$. jejuni transferred from chicken leg in various tasks of the cross contamination study.

\begin{tabular}{lcccc}
\hline \multicolumn{1}{c}{$\begin{array}{c}\text { Sample/Transfer } \\
\text { Description }\end{array}$} & Number of & \multicolumn{3}{c}{ Concentration of $C}$. \\
& Observations & \multicolumn{2}{c}{ jejuni (MPN/g) } \\
& Min & Med & Max \\
\hline Chicken Leg & 5 & $<3.0$ & $<3.0$ & $<3.0$ \\
$\begin{array}{l}\text { Chicken Leg to } \\
\text { Cutting Board }\end{array}$ & 5 & $<3.0$ & $<3.0$ & $<3.0$ \\
$\begin{array}{l}\text { Chicken Leg cut with } \\
\text { knife }\end{array}$ & 5 & $<3.0$ & 3 & 3 \\
$\begin{array}{l}\text { Cucumber cut with } \\
\text { knife on cutting board }\end{array}$ & 5 & $<3.0$ & $<3.0$ & $<3.0$ \\
Latex Gloves & 5 & $<3.0$ & $<3.0$ & $<3.0$ \\
\hline
\end{tabular}

On the other hand, the transfer rate from the cutting board and from the knife to the cucumber was lower compared to the transfer rates from the contaminated livestock products to the cutting board or to the knife (Tables 1 and 2). Similarly, the transfer rate of $C$. jejuni from the naturally contaminated chicken liver and chicken leg to the latex gloves used throughout the processing of the chicken liver and chicken leg were low (Tables 1 and 2). This is presumably due to the surface of the cucumber and latex gloves that do not favour the adherence of the $C$. jejuni. Jensen et al. (2017) conducted a similar study on the transfer rate from contaminated food to latex gloves reported that the transfer rate was only $1 \%$ or even lower which supports our findings. The transfer rate from hand to food will result a higher transfer rate which could be that the pathogens are being provided with the source of nutrients from the food that in favour for their growth. This theory is yet to be confirmed as the mechanism of transfer is complicated by the usual host factors in studying cross contamination including surface type, bacterial species, moisture level, pressure and friction (Montville and Schaffner, 2003) 
The results also revealed the random nature of cross contamination events is more likely to happen when initial load of pathogen is low. This is evidently supported by Mackintosh and Hoffman (1984) whereby the lowest inoculum of bacteria had the highest transfer rate while the highest inoculum of bacteria had the lowest transfer rate. Montville and Schaffner (2003) explained that the possible cause for reduced transfer at high inoculum level could be the improved attachment to the donor surface. This is to say that at lower inoculum levels, the attachment of the bacteria is not firm, having them to detach off easily from the donor surface, leading to higher transfer rates.

Raw produce itself may be contaminated either during pre- or postharvest operations (Doyle and Erickson, 2008; Elexson et al., 2017; Norshafawati et al.,2017) and hence, could lead to cross contamination and foodborne illness when kitchen utensils used in their preparation are subsequently used on other food products that would be consumed raw. To address the potential cross contamination by kitchen utensils in the home, this study illustrates the extent of naturally contaminating $C$. jejuni in chicken liver and chicken leg cross contaminating kitchen utensils. It should be noted that our experimental design was significantly different in which most previous studies, samples to be studied were inoculated to study on the crosscontaminating factors. But then again, our research results used the natural pathogen load of bacterial contaminants that provided information of the real scenario. This point on the transfer of $C$. jejuni from naturally contaminated raw vegetables to cucumber cut on the same cutting board was also previously demonstrated by Chai et al. (2008). Despite that, the present study did not consider the possibility that the initial microbial load on the samples may be reduced by the process of washing, a control point for reducing the risk of cross contamination in the kitchen environment. The data gap should be considered if quantitative microbial risk assessment is to be performed.

Household cross contaminations rarely lead to an outbreak or it could be underreported. However, consumer awareness and household practices are critical for the prevention of foodborne diseases in home, since consumer handling can disseminate Campylobacter from naturally contaminated chicken parts to food contact surfaces in the kitchen (Gorman et al., 2002). Transfer of microorganisms from hands to surfaces such as refrigerator/freezer handles, table cloths and washing items poses a continuous risk of food contamination or spreading of microorganisms from one meal to the next. According to the quantitative risk assessment study conducted by Signorini et al. (2013), the amount of Campylobacter spp. to which a consumer was exposed in a single serving of poultry with salad was a function of the original number of Campylobacter spp. in the poultry carcass at retail and the subsequent effects of storage and handling. It is understood from this statement that the chances of getting campylobacteriosis will be high when inoculums are higher. The probability of suffering from campylobacteriosis could be at 0.5 rate. This regards the high importance of food safety education among food handlers and consumers as a need to conserve public health.

\section{Acknowledgements}

The research work was funded by Kakenhi Grant-in-Aid for Scientific Research (KAKENHI 24249038), Japan Society for the Promotion of Sciences and grant-in-aid of Ministry of Health, Labour and Welfare, Japan and in part Fundamental Research Grant Project (FRGS/1/2014/SG05/ UPM/01/2/5524559) from the Ministry of Education, Malaysia.

\section{References}

Bloomfield, S.F. (2003). Home hygiene: a risk approach. International Journal of Hygiene and Environmental Health, 206, 1-8.

Centers for Disease Control and Prevention (CDC) (2014). Campylobacter. Retrieved on March 8, 2017 from https://www.cdc.gov/foodsafety/diseases/ campylobacter/

Centers for Disease Control and Prevention (CDC) (2016). Burden of Foodborne Illness: Findings. Retrieved on March 8, 2017 from https://www.cdc. gov/foodborneburden/2011-foodborne-estimates. html\#modalIdString_CDCTable_4

Chai, L.-C., Lee, H.-Y., Ghazali, F.M., Abu Bakar, F., Malakar, P.K., Nishibuchi, M., Nakaguchi, Y. and Son, R. (2008). Simulation of cross contamination and decontamination of Campylobacter jejuni during handling of contaminated raw vegetables in a domestic kitchen. Journal of Food Protection, 71, 2448-2452.

Doyle, M.P. and Erickson, M.C. (2008). Summer meeting 2007- the problems with fresh produce: an overview. Journal of Applied Microbiology, 105, 317-330.

Elexson, N., Nik Yuhanis, F.N., Malcolm, T.T.H., New, C.Y., Chang, W.S., Ubong, A., Kuan, C.H., Loo, Y.Y., Thung, T.Y. and Son, R. (2017). Occurrence of Escherichia coli harbouring stx genes in popiah, a Malaysian street food. Food Research, 1(1), 29-32. 
Fischer, A.R.H., De Jong, A.E.I., Van Asselt, E.D., De Jonge, R., Frewer, L.J. and Nauta, M.J. (2007). Food safety in the domestic environment: an interdisciplinary investigation of microbial hazards during food preparation. Risk Analysis, 27, 1065-1082.

Gorman, R., Bloomfield, S. and Adley, C.C. (2002). A study of cross contamination of food-borne pathogens in the domestic kitchen in the Republic of Ireland. International Journal of Food Microbiology, 76, 143150.

Government of Malaysia (2004). Foodborne disease monitoring and surveillance systems. FAO/WHO Regional Conference on Food Safety for Asia and Pacific, 24-27 May 2004, p. 9. Seremban, Malaysia: $\mathrm{FAO} / \mathrm{WHO}$

Jensen, D.A., Danyluk, M.D., Harris, L.J. and Schaffner, D.W. (2017). Quantifying bacterial cross contamination rates between fresh-cut produce and hands. Journal of Food Protection, 80(2), 213-219

Linton, D., Lawson, A. J., Owen, R. J. and Stanley, J. (1997). PCR detection, identification to species level and fingerprinting of Campylobacter jejuni and Campybacter coli direct from diarrheic samples. Journal of Clinical Microbiology, 35, 2568-2572.

Mackintosh, C. A. and Hoffman, P. N. (1984). An extended model for transfer of micro-organisms via the hands: differences between organisms and the effect of alcohol disinfection. The Journal of Hygiene, 92, 345355.

Montville, R. and Schaffner, D.W. (2003). Inoculum Size Influences Bacterial Cross Contamination between surfaces. Applied and Environmental Microbiology, 69(12), 7188-7193

Norshafawati, R., Noorlis, A., Kuan, C.H., New, C.Y., Mingkwan, Y., Nakaguchi, Y., Nishibuchi, M. and Son, R. (2017). Isolation and antibiotic susceptibility profile of Vibrio cholerae isolated from catfish (Pangasius hypophthalmus). Food Research, 1(1), 2327.

Nur Ilida, M. and Faridah, M.S. (2012). Prevalence of Campylobacter jejuni in chicken meat and chickenbased products. Journal of Tropical Agriculture and Food Science, 40(1), 63- 69

Perez-Rodríguez, F., Valero, A., Carrasco, E., García, R.M. and Zurera, G. (2008). Understanding and modelling bacterial transfer to foods: a review. Trends in Food Science and Technology, 19, 131-144.

Signorini, M.L., Zbrun, M.V., Romero-Scharpen, A., Olivero, C., Bongiovanni, F., Sotoa, L.P., Frizzoa, L.S. and Rosminia, M.R. (2013). Quantitative risk assessment of human campylobacteriosis by consumption of salad cross-contaminated with thermophilic Campylobacter spp. from broiler meat in Argentina. Preventive Veterinary Medicine, 109, $37-$ 46

Wingstrand, A., Neimann, J., Engberg, J., Nielsen, E.M., Gerner-Smidt, P., Wegener, H.C. and Molbak, K. (2006). Fresh chicken as main risk factor for campylobacteriosis, Denmark. Emerging Infectious Diseases, 12, 280-285 